\title{
REDUÇÃO DO TEMPO NO PROCESSO DE COZIMENTO DE MORTADELA E AVALIAÇÃO DA QUALIDADE FINAL DO PRODUTO
}

\section{REDUCTION OF MORTADELLA COOKING TIME AND EVALUATION OF THE FINAL PRODUCT QUALITY}

\author{
Diones Orsolin ${ }^{1}$ \\ Clarice Steffens ${ }^{1 *}$ \\ Clarissa Dalla Rosa ${ }^{1}$ \\ Juliana Steffens ${ }^{1}$ \\ 1Programa de Pós-Graduação em Engenharia de Alimentos, Universidade Regional Integrada do Alto \\ Uruguai e das Missões (URI), Erechim, RS, Brasil \\ *Autora para correspondência - claristeffens@yahoo.com.br
}

\begin{abstract}
Resumo
Em indústrias de alimentos, o processo de cozimento é um dos mais importantes para a conservação e garantia da qualidade do produto final, principalmente de mortadelas. Porém, este é um processo que necessita de elevados investimentos em equipamentos modernos, além de apresentarem gastos com energia elétrica e vapor. Neste contexto, o objetivo deste trabalho foi propor um método de cozimento das mortadelas elaboradas com carne suína e com carne de frango com tempo reduzido pelo aumento da temperatura no interior da estufa. Foram realizadas avaliações do comportamento da atividade de água $\left(\mathrm{A}_{\mathrm{w}}\right), \mathrm{pH}$ e textura das mortadelas ao longo da vida de prateleira. A partir dos resultados obtidos, foi possível verificar que tanto as mortadelas cozidas pelo processo atual quanto as que passaram pelo processo de cozimento em tempo reduzido não apresentaram diferenças significativas com 95\% de confiança para nenhuma das características analisadas. Sendo assim, todos os tratamentos apresentaram valores próximos e podem ser considerados dentro dos padrões estabelecidos de qualidade dos produtos, tanto para a atividade de água quanto para $\mathrm{pH}$ e textura.
\end{abstract}

Palavras-chave: atividade de água; carne de frango; carne suína; textura.

\begin{abstract}
In food industry, the cooking is one of the most important processes for the conservation and quality assurance of the final product, especially mortadella. However, this process requires high investment in modern equipment besides having energy and steam expenses.. In this context, the objective of this study was to propose a cooking method of mortadella produced with pork and chicken, by reducing time and increasing temperature inside the baking oven. Evaluations of behavior of water activity, $\mathrm{pH}$ and texture of the mortadella were carried out throughout shelf life. From the results, we found that both pork and chicken mortadella that were cooked by the current process and those that passed through the cooking process with reduced time showed no significant differences at the level of $95 \%$ confidence for the analyzed characteristics. Therefore, all treatments had similar values and can be considered within the established standards of product quality for both water activity and for $\mathrm{pH}$ and texture.
\end{abstract}

Keywords: chicken meat; pork meat; texture; water activity. 
Enviado em: 18 junho 2014

Aceito em: 10 agosto 2015

\section{Introdução}

O aumento da demanda de carne, principalmente de aves e suínos, faz com que as indústrias do mundo inteiro invistam, cada vez mais, em tecnologias capazes de agregar valor aos produtos. A industrialização é a principal alternativa para o escoamento da matéria prima, além de proporcionar um aumento na vida útil dos produtos. Atualmente, o consumidor tem à sua disposição uma enorme gama de derivados cárneos, que lhes são oferecidos pelo mercado de indústrias frigoríficas, dentre eles, presuntos, apresuntados, linguiças, salsichas, mortadelas, entre outros ${ }^{(1)}$.

Os produtos cárneos emulsionados, como as mortadelas, são bastante populares, sendo consumidos tanto no âmbito doméstico como no mercado de alimentação rápida, representando um importante segmento da industrialização de carnes. Estima-se que o consumo per capita anual brasileiro seja de aproximadamente $5 \mathrm{~kg}$ de produtos cárneos emulsificados, mostrando fazer parte integrante da dieta e ter considerável importância na economia ${ }^{(2)}$.

A qualidade final da mortadela depende diretamente do seu processo de cozimento, pois elevadas temperaturas e/ou um período muito elevado em que o embutido permaneça nessa temperatura faz com que ocorra uma má formação de gelatina e separação da gordura ${ }^{(3)}$. O cozimento tem por objetivo o desenvolvimento da cor, a pasteurização e a coagulação das proteínas. A coagulação das proteínas da carne é a maior transformação que o cozimento causa em um produto emulsionado. Tal transformação ocorre em torno dos $60^{\circ} \mathrm{C}$ e, por este motivo, não é importante o estabelecimento de uma temperatura final de cozimento. Entretanto, em quase toda formulação de embutido, um dos ingredientes é o amido, que só coagula por volta de $67^{\circ} \mathrm{C}$; devido a isso, ficou estabelecido que a temperatura final de cozimento estaria entre $68^{\circ} \mathrm{C}$ e $72{ }^{\circ} \mathrm{C}^{(3)}$.

A escolha do método de cozimento depende não somente do produto a ser cozido, mas também do tipo de envoltório (tripa), custo do processo e capacidade de produção. As estufas mais modernas oferecem uma boa gama de possibilidades de trabalho, desde o calor seco até o calor com umidade relativa controlada, o que traz grandes vantagens quando bem explorado ${ }^{(3)}$.

$\mathrm{O}$ cozimento pode ser dividido em etapas, em que as temperaturas e os tempos variam de acordo com o equipamento utilizado, o calibre e o peso da peça. É importante que não seja ultrapassado o limite de $90{ }^{\circ} \mathrm{C}$ na estufa ou meio de cozimento para que não ocorra quebra da emulsão e outros defeitos que levariam à perda total do lote ${ }^{(3)}$.

Alguns parâmetros como $\mathrm{pH}$, atividade de água $\left(\mathrm{A}_{\mathrm{w}}\right)$ e textura são muito importantes em produtos emulsionados. $\mathrm{O}$ pH de um alimento não exerce apenas influência sobre a velocidade de multiplicação dos microrganismos, mas também interfere na qualidade dos alimentos, durante o armazenamento, tratamento térmico, dessecação ou durante qualquer outro tipo de tratamento, ou seja, é também responsável direto pela deterioração dos produtos. Com a determinação do $\mathrm{pH}$ nos alimentos, é possível a avaliação da microbiota predominante, o potencial e a provável natureza dos processos de deterioração que ele poderá sofrer, assim como o tipo, a intensidade e os parâmetros do processamento térmico a que deve ser submetido ${ }^{(4)}$.

A água presente nos alimentos pode ser analisada como $\mathrm{A}_{\mathrm{w}}$ e é um indicador de como a água afeta processos bioquímicos e outros fatores, como a disponibilidade de nutrientes para os microrganismos ${ }^{(5)}$. A cinética de muitas reações depende da atividade de água, tais como inativação de enzimas, destruição de microrganismos, reação de Maillard, gelatinização do amido e desnaturação de proteínas durante o cozimento $^{(6)}$. Cada microrganismo tem uma $\mathrm{A}_{\mathrm{w}}$ máxima, ótima e mínima na qual se desenvolve mais rapidamente ${ }^{(4)}$.

A textura é um dos principais parâmetros para a avaliação da qualidade de alimentos sendo que a aceitação dos consumidores para um determinado alimento é extremamente dependente das suas 
características de fatiabilidade, maciez entre outros ${ }^{(7)}$.

A sobrevivência das empresas no mercado competitivo atual está diretamente ligada à produção de itens de qualidade com baixo custo; assim, os processos utilizados para a obtenção de produtos industrializados apresentam constantes transformações ${ }^{(8)}$. Portanto, as empresas, para sobreviverem, prezam cada vez mais pela redução da utilização de energias não renováveis. Dentro deste contexto, o objetivo deste estudo foi propor um método de cozimento com tempo reduzido e aumento da temperatura no interior da estufa.

\section{Material e Métodos}

O presente trabalho foi desenvolvido em uma empresa de embutidos do Estado de Santa Catarina, onde foram realizados estudos do tempo de redução do cozimento das mortadelas de carne de frango e de carne suína com diferentes formulações.

Na produção das mortadelas com carne de frango e carne suína, a temperatura da massa embutida foi definida como sendo a temperatura limite inferior de $-2{ }^{\circ} \mathrm{C}$ e limite superior de $14{ }^{\circ} \mathrm{C}$; tais condições correspondem aos extremos permitidos pelo processo. Logo, foi necessário estabelecer a quantidade de matéria prima resfriada e congelada utilizadas nas formulações para se atingir as temperaturas extremas para as formulações de mortadela suína (Tabela 1) e para formulações de mortadela de carne de frango (Tabela 2).

Tabela 1: Composição das matérias primas utilizadas na elaboração das formulações de mortadela com carne suína, Chapecó/SC, 2012

\begin{tabular}{lccc}
\hline Matéria prima & Condição & $\begin{array}{c}\text { (\%) de matéria prima para } \\
\text { atingir T } \mathbf{- 2}{ }^{\circ} \mathbf{C}\end{array}$ & $\begin{array}{c}\text { (\%) de matéria prima } \\
\text { para atingir T 14 }{ }^{\circ} \mathbf{C}\end{array}$ \\
\hline Músculo suíno & Congelada & 3,1 & 3,1 \\
CMS - Suíno & Resfriado & 7,6 & 7,6 \\
Miúdos (figado, rim) & Congelada & 3,1 & 3,1 \\
Pele & Resfriada & 0,0 & 9,2 \\
Gordura suína & Congelada & 4,6 & 4,6 \\
CMS - aves & Congelada & 45,9 & 22,9 \\
CMS - aves & Resfriado & 26,6 & 49,6 \\
\hline
\end{tabular}

Tabela 2: Composição das matérias primas utilizadas na elaboração das formulações de mortadela com carne de frango, Chapecó/SC, 2012

\begin{tabular}{cccc}
\hline Matéria prima & Condição & $\begin{array}{c}\text { (\%) de matéria prima } \\
\text { para atingir T } \mathbf{- 2}^{\mathbf{}} \mathbf{C}\end{array}$ & $\begin{array}{c}\text { (\%) de matéria prima } \\
\text { para atingir } \mathbf{~} \mathbf{~ 1 4}^{\circ} \mathbf{C}\end{array}$ \\
\hline Cortes de aves s/pele & Resfriada & 17,0 & 17,0 \\
Recorte de aves s/pele & Resfriada & 10,5 & 27,5 \\
Recorte de aves s/pele & Congelada & 17,0 & 0,0 \\
CMS - aves & Congelada & 54,4 & 0,0 \\
CMS - aves & Resfriada & 1,0 & 55,4 \\
\hline
\end{tabular}


Após estabelecidas as formulações das mortadelas com carne suína e de frango para a obtenção das temperaturas das massas desejadas, foi iniciada a produção das mesmas, conforme demonstrado na Figura 1.

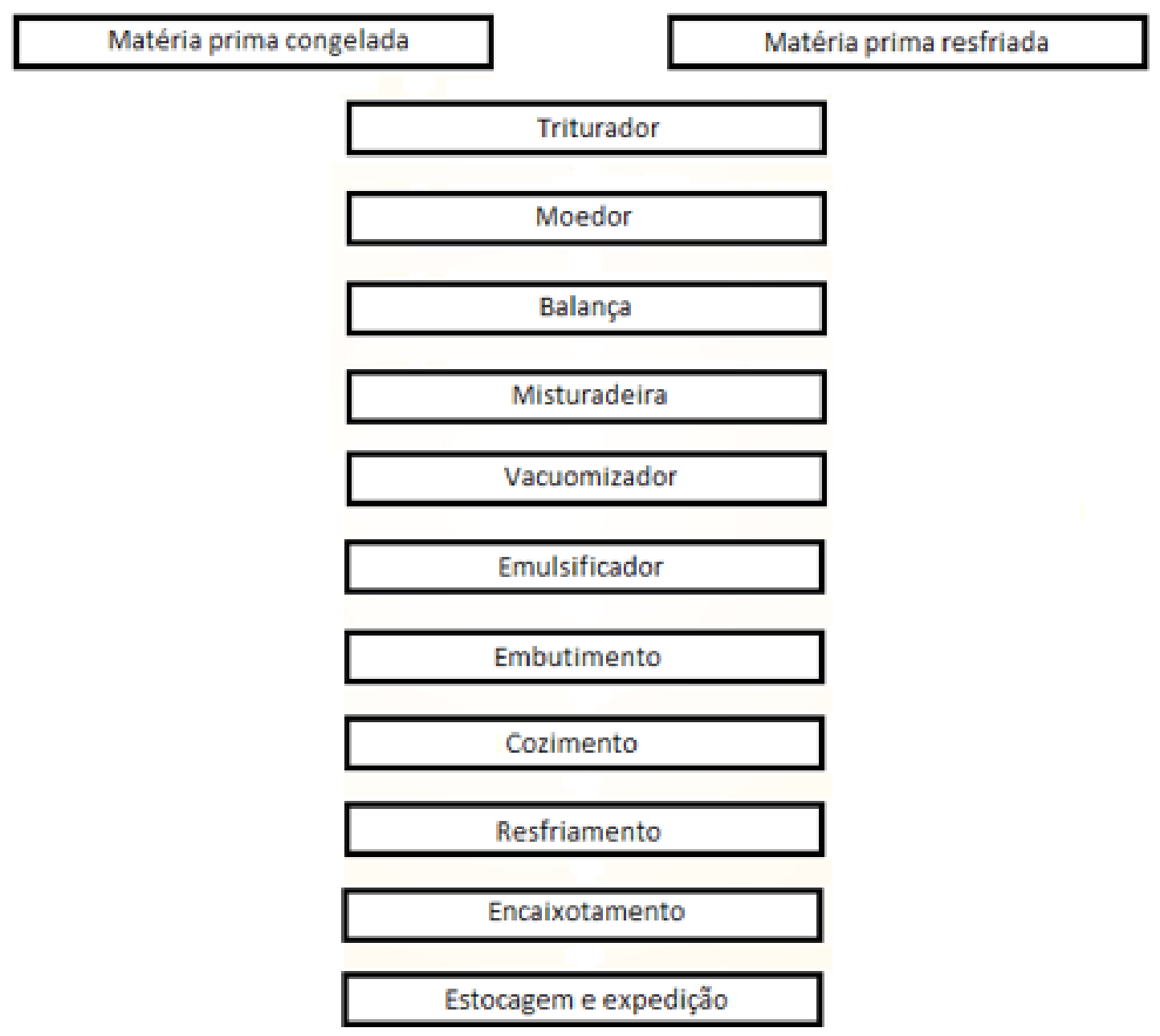

Figura 1: Fluxograma de produção das mortadelas.

As matérias primas congeladas e/ou resfriadas foram trituradas e transportadas até o moedor (Hobart), cuja função é garantir a granulometria desejada para cada matéria prima antes de serem enviadas para a próxima etapa do processo, e posteriormente pesadas e misturadas em misturadeira (Beccaro), formando assim a massa. Durante o processo de mistura, foram adicionados os condimentos, aditivos e conservantes (dados confidenciais).

Após o término da mistura, a massa passou pelo processo de vacuomização (Cozzini), com misturador do tipo pá e bomba de vácuo dupla para a retirada de bolhas de ar do meio da massa e pelo emulgador (Cozzini) para refinar e realizar a emulsão da massa. Posteriormente, a massa foi conduzida para o processo de embutimento.

No embutimento, foi utilizada tripa artificial, utilizando-se uma embutideira hidráulica acoplada (Hantdmann e Granpeadeira da Marca Poly-Clip) de funil com calibre 36 milímetros, para obtenção de mortadelas com 2500 gramas, com calibre de 97 milímetros de diâmetro e comprimento de 380 milímetros. Em seguida, as mortadelas sofreram o processo de cozimento em estufa (MAURER), utilizando-se vapor saturado, onde permaneceram até atingirem a temperatura no núcleo do produto de, no mínimo, $74{ }^{\circ} \mathrm{C}$ e processo de resfriamento, em que permaneceram até atingirem a temperatura no núcleo do produto de, no mínimo, $25^{\circ} \mathrm{C}$. Este controle de temperatura foi feito com o auxílio de 
sensores dispostos no interior da estufa. Por fim, as mortadelas foram acondicionadas em caixas de papelão e mantidas em câmara de estocagem sob temperatura de, no máximo, $7^{\circ} \mathrm{C}$ até extinção do prazo de validade.

Os prazos de validade para as mortadelas elaboradas com carne de frango e as com carne suína foram estabelecidos pelo departamento de pesquisa e desenvolvimento da Aurora Alimentos, levando em consideração as velocidades das reações de deterioração e modificações das características físicoquímicas de ambos os tipos de mortadelas, sendo que a validade da mortadela com carne de frango foi estimada em 60 dias e a mortadela com carne suína em 90 dias.

No processo de cozimento, foram estudados dois tipos de cozimento, denominados como processo padrão e com redução de tempo de cozimento (otimizado), ambos utilizando as formulações com carne suína e de frango a -2 e $14{ }^{\circ} \mathrm{C}$. O processo de cozimento das mortadelas foi realizado em estufas MAURER, em forma de bateladas, em que cada batelada comporta dez carros carregados com mortadelas distribuídas de forma que as peças não encostassem umas as outras. Após o carregamento completo da estufa, foi acionado o programa de cozimento com controle automático de todos os parâmetros (tempo e temperatura definidos em cada etapa).

O processo de cozimento padrão foi constituído de quatro passos nos quais a temperatura no interior da estufa foi aumentada gradativamente até se atingir a temperatura de $80{ }^{\circ} \mathrm{C}$ no interior do produto, conforme demonstrado a seguir:

- Passo $1=30$ minutos a $65^{\circ} \mathrm{C}$;

- Passo $2=30$ minutos a $70^{\circ} \mathrm{C}$;

- Passo $3=30$ minutos a $75^{\circ} \mathrm{C}$;

- Passo $4=100$ minutos a $80^{\circ} \mathrm{C}$.

O tempo total de cozimento das mortadelas por batelada é de 190 minutos, garantindo que a temperatura no núcleo das mesmas alcance, no mínimo, $74{ }^{\circ} \mathrm{C}$, sendo que este valor é definido e estabelecido pela empresa como a temperatura mínima que o produto deve atingir para finalizar o processo, além de garantir um produto com melhor cor, textura e eliminação de microrganismos patogênicos.

O processo otimizado foi constituído de cinco passos:

- Passo $1=30$ minutos a $65^{\circ} \mathrm{C}$;

- Passo $2=30$ minutos a $70^{\circ} \mathrm{C}$;

- Passo $3=30$ minutos a $75^{\circ} \mathrm{C}$;

- Passo $4=30$ minutos a $80^{\circ} \mathrm{C}$;

- Passo $5=60$ minutos a $85^{\circ} \mathrm{C}$.

Após o cozimento, as mortadelas foram resfriadas até se atingir a temperatura no núcleo do produto de, no mínimo, $25^{\circ} \mathrm{C}$. Por fim, as mortadelas foram acondicionadas em caixas de papelão e mantidas em uma câmara de estocagem de 2 a $7^{\circ} \mathrm{C}$ por 90 ou 60 dias, dependendo da mortadela.

As análises de $\mathrm{A}_{\mathrm{w}}$ e $\mathrm{pH}$ foram realizadas nos laboratórios da empresa de embutidos. As análises de textura foram realizadas no laboratório de análises de carnes da EMBRAPA em Concórdia (SC). Todas as análises foram realizadas em triplicata para cada tratamento, tanto para as mortadelas de carne suína quanto para as mortadelas de carne de frango. As análises de $\mathrm{A}_{\mathrm{w}}$, textura e $\mathrm{pH}$ foram realizadas até o final do prazo de validade sendo que, para a mortadela de carne suína foram realizadas análises nos tempos 0, 30, 60 e 90 dias após a data de fabricação e, para a mortadela de carne de frango, foram realizadas análises nos tempos 0,30, 45 e 60 dias após a data de fabricação.

$\mathrm{AA}_{\mathrm{w}}$ foi determinada utilizando-se aparelho da marca Testo ${ }^{\circledR}$, modelo 650 , calibrado em temperatura de aproximadamente $25^{\circ} \mathrm{C}^{(9)}$. Este equipamento aplica o princípio do ponto de orvalho, em que a água é condensada em superfície espelhada e fria, sendo detectada por sensor infravermelho.

$\mathrm{O} \mathrm{pH}$ foi determinado utilizando-se aparelho da marca Datalogging $\mathrm{pH} / \mathrm{mV}$ METER 9661. Foram pesadas dez gramas de amostra e homogeneizadas com cem mililitros de água destilada. Os eletrodos foram inseridos na solução e a leitura realizada. As análises foram realizadas em temperatura aproximada de $20^{\circ} \mathrm{C}^{(10)}$.

A textura das mortadelas para os diferentes tipos de tratamentos foi avaliada pela medida da força de cisalhamento (força máxima necessária para o cisalhamento das amostras). As amostras foram 
cortadas em pedaços de 1x1x2 $\mathrm{cm}^{2}$ (altura, largura e comprimento). As análises foram realizadas em sextuplicata em Texturômetro TA-XT plus (Texture analyser), utilizando-se como probe a lâmina Warner Bratzler.

Os resultados foram tratados estatisticamente pela Análise de Variância (ANOVA) e a comparação das médias pelo Teste de Tukey com nível de significância de $95 \%(\mathrm{p}<0,05)$, utilizando-se o programa Statistica ${ }^{\circledR} 8.0$ (STATSOFT Inc).

\title{
Resultados e Discussão
}

A Figura 2 apresenta valores de $\mathrm{A}_{\mathrm{w}}$ ao longo do tempo de vida útil, para tratamento das mortadelas de carne suína (2a) e mortadela de carne de frango (2b). Verificou-se que a faixa de variação da $\mathrm{A}_{\mathrm{w}}$ entre os diferentes tratamentos e ao longo da vida útil para as mortadelas com carne suína (Figura 2a) foi de 0,969 a 0,975 , e observou-se diferença significativa a $95 \%$ de confiança para os diferentes tratamentos.

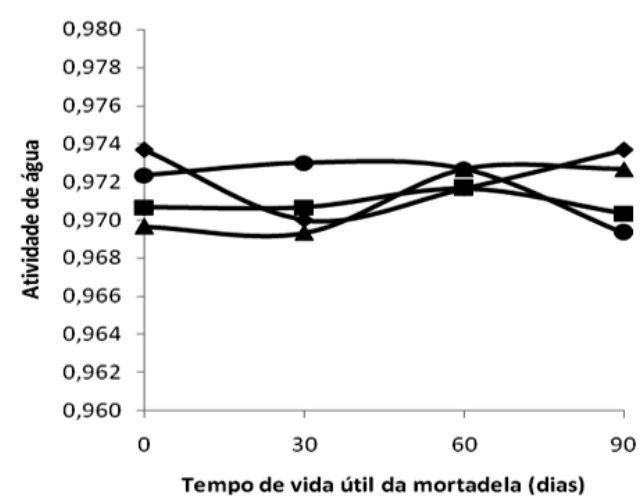

(a)

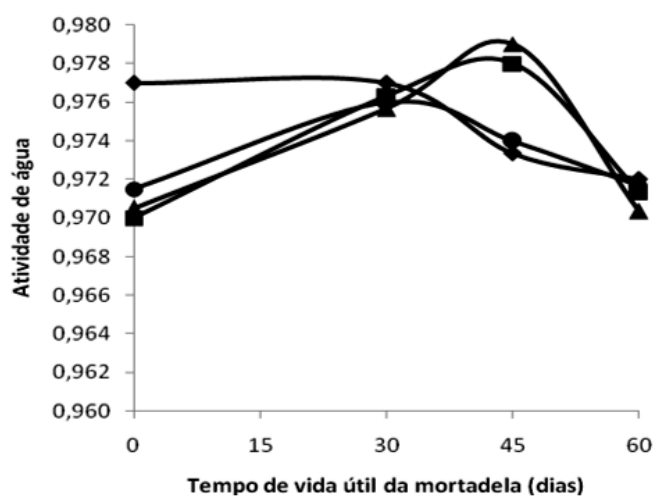

(b)

\begin{abstract}
Figura 2: Perfil da Aw para cada tratamento da mortadela com carne suína (a) e mortadela de carne de frango (b) ao longo de sua vida útil. • Formulação padrão com massa congelada a -2 ${ }^{\circ} \mathrm{C}$, — Formulação padrão com massa resfriada a $14{ }^{\circ} \mathrm{C}, \boldsymbol{\Delta}$ Formulação otimizada com massa congelada a $-2{ }^{\circ} \mathrm{C}$, $\bullet$ Formulação otimizada com massa resfriada a $14{ }^{\circ} \mathrm{C}$.
\end{abstract}

Viuda-Martos et al. ${ }^{(11)}$ estudaram o efeito da adição de fibras de laranja (1\%), óleo essencial de alecrim $(0,02 \%)$ e óleo essencial de tomilho $(0,02 \%)$ na $A_{w}$ comparadas com mortadela padrão de carne suína. Os autores verificaram que $\mathrm{A}_{\mathrm{w}}$ da padrão foi de 0,89 enquanto que as adicionadas de fibra de laranja e óleo essencial de alecrim e tomilho foram de 0,87 , valores inferiores aos encontrados no presente estudo. Fiorda e De Siqueira ${ }^{(12)}$, estudando mortadela elaborada com carne mecanicamente separada de ave e suíno, encontraram $A_{w}$ de 0,957 , valores inferiores aos encontrados neste estudo, o que provavelmente pode estar associado à composição da mortadela. Por meio dos valores de $\mathrm{A}_{\mathrm{w}}$ analisados, verificou-se que a variação de $\mathrm{A}_{\mathrm{w}}$ ao longo do tempo de vida útil é baixa para todos os tipos de tratamentos para a mortadela suína. Portanto, os valores de $\mathrm{A}_{\mathrm{w}}$ podem ser considerados normais para este tipo de produto $^{(12)}$ e encontram-se de acordo com os padrões de qualidade estabelecidos para os produtos da empresa.

Para a mortadela de frango (Figura 2b), a faixa de variação da Aw entre os diferentes tratamentos e ao longo da vida útil foi de 0,976 e 0,986 e não houve diferença significativa a $95 \%$ de confiança. Estes valores podem ser considerados normais e dentro dos padrões estabelecidos pela qualidade dos produtos empresa.

As mortadelas são classificadas como de alta $\mathrm{A}_{\mathrm{w}}$, o que pode favorecer a proliferação de 
microrganismos $^{(13)}$; portanto, elas necessitam ser armazenadas sob refrigeração. De acordo com Wilson e Demmig-Adams ${ }^{(14)}$, a quantidade de água presente no alimento também pode afetar a estabilidade oxidativa dos lipídios e, segundo Dewi e Ismail ${ }^{(15)}$, a oxidação lipídica reduz o tempo de vida do produto e a qualidade nutritiva do mesmo.

A Figura 3 apresenta os valores de $\mathrm{pH}$ ao longo do tempo de vida útil, para cada tratamento das mortadelas com carne suína (3a) e carne de frango (3b). Verificou-se que a faixa de variação do $\mathrm{pH}$ entre os diferentes tratamentos e ao longo da vida útil das mortadelas de carne suína (Figura 3a) foi de 6,42 a 6,63, enquanto que para as mortadelas de carne de frango foram de 6,32 a 6,44. Esta diferença de $\mathrm{pH}$ encontrada para as mortadelas se deve principalmente às diferenças existentes na composição entre a formulação da mortadela com carne suína e a formulação da mortadela com carne de frango (quantidades e tipos de ingredientes, tais como os antioxidantes, acidulantes e estabilizantes para cada tipo de mortadela).

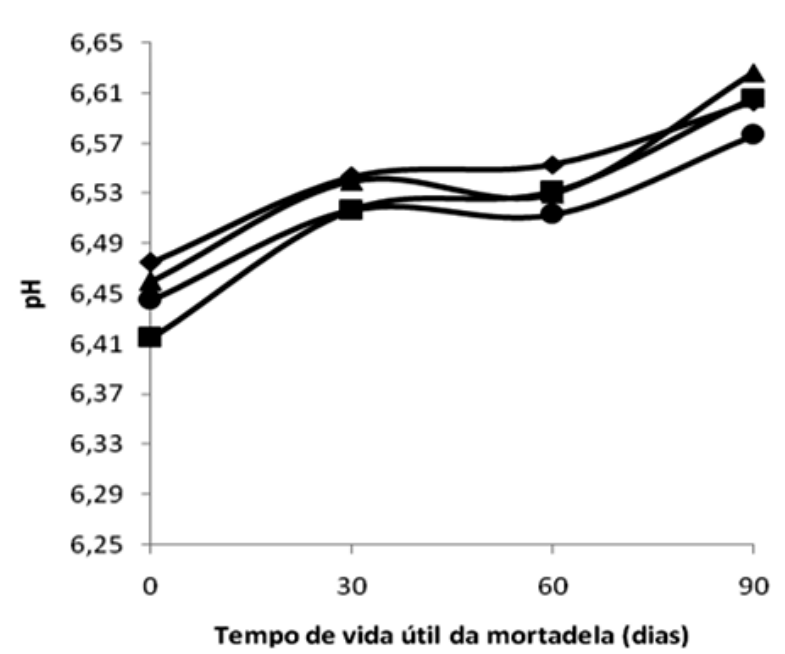

(a)

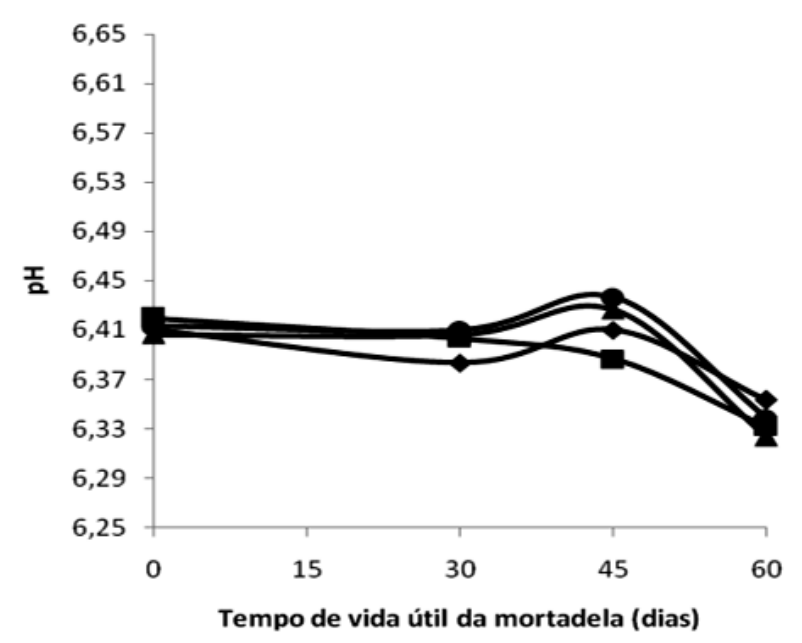

(b)

Figura 3: Perfil do $\mathrm{pH}$ para cada tratamento da mortadela com carne suína (a) e mortadela de carne de frango (b) ao longo de sua vida útil. • Formulação padrão com massa congelada a -2 ${ }^{\circ} \mathrm{C}$, — Formulação padrão com massa resfriada a $14{ }^{\circ} \mathrm{C}, \boldsymbol{\Delta}$ Formulação otimizada com massa congelada a $-2{ }^{\circ} \mathrm{C}, \bullet$ Formulação otimizada com massa resfriada a $14{ }^{\circ} \mathrm{C}$.

Os valores encontrados para cada tipo de tratamento e para cada tipo de mortadela ao longo armazenamento podem ser considerados normais e dentro dos níveis aceitáveis para uma boa conservação de alimentos processados ${ }^{(16)}$. Em relação às mortadelas com carne suína e com carne de frango nos diferentes tratamentos, foi observado que não houve diferença significativa a 95\% entre os valores de $\mathrm{pH}$.

A Figura 4 apresenta os valores de textura ao longo do tempo de vida útil, para cada tratamento das mortadelas com carne suína (4a) e carne de frango (4b). Verificou-se que a faixa de variação da textura entre os diferentes tratamentos e ao longo da vida útil das mortadelas com carne suína foi de 0,17 a 0,22 Kgf (Figura 4a), enquanto que a das mortadelas de carne de frango foi de 0,24 a 0,30 Kgf (Figura 4b). O comportamento da textura ao longo do tempo da vida útil e para cada tratamento está de acordo com os padrões de qualidade estabelecidos para os produtos da empresa.

Baseando-se no que foi verificado, pode-se afirmar que não existe diferença ao nível de significância de $95 \%$ entre os valores de textura para as mortadelas com carne suína e de carne de frango nos diferentes tratamentos.

Saldaña et $a^{(17)}$ avaliaram o perfil de textura em mortadelas de carne suína tradicional e light por meio de 11 provadores treinados e por meio de texturômetro e verificaram que a mortadela light apresentou maior dureza em relação a tradicional. 


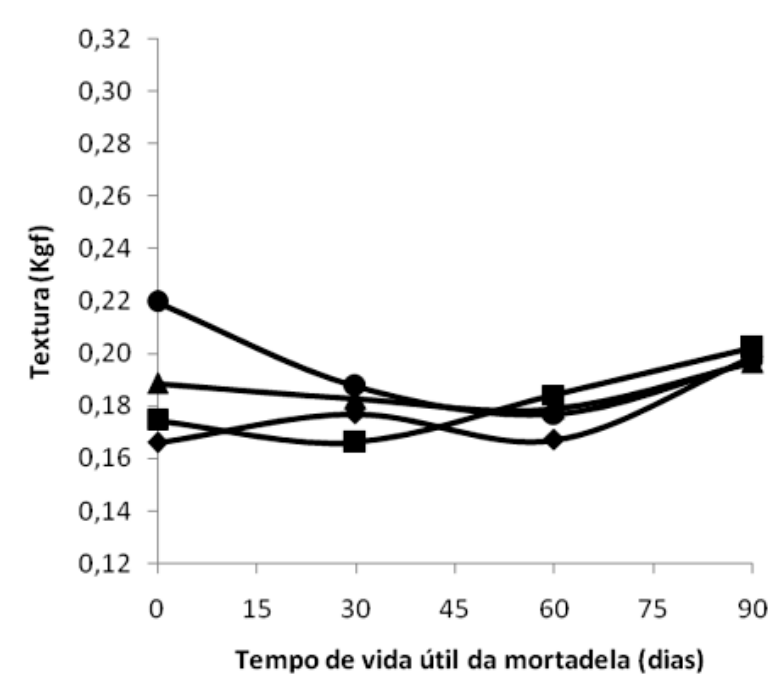

(a)

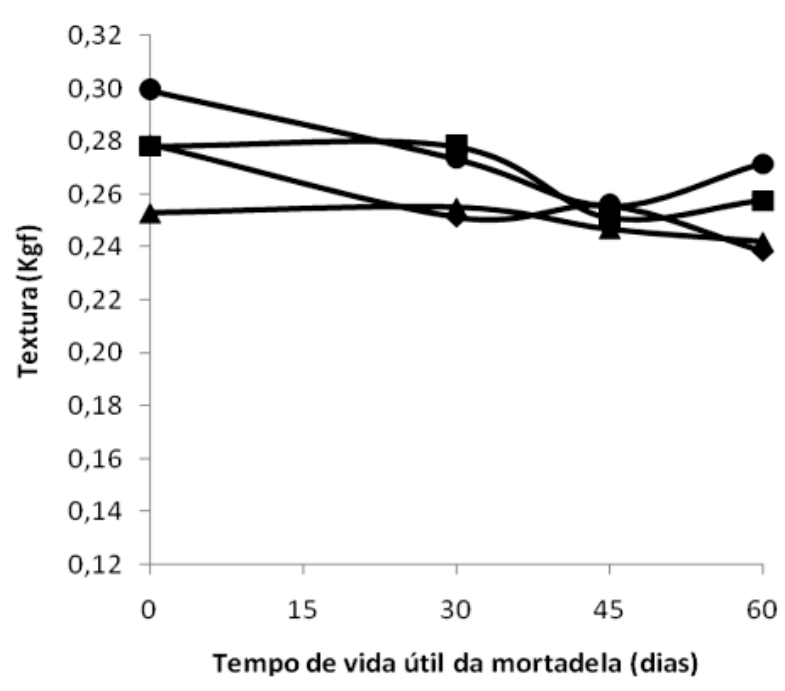

(b)

Figura4: Perfil da textura para cada tratamento da mortadela com carne suína (a) e mortadela de carne de frango (b) ao longo de sua vida útil. $\bullet$ Formulação padrão com massa congelada a -2 ${ }^{\circ} \mathrm{C}$, — Formulação padrão com massa resfriada a $14{ }^{\circ} \mathrm{C}, \boldsymbol{\Delta}$ Formulação otimizada com massa congelada a $-2{ }^{\circ} \mathrm{C}$, • Formulação otimizada com massa resfriada a $14{ }^{\circ} \mathrm{C}$.

Comparando os resultados de textura nos diferentes tratamentos e ao longo do tempo de vida útil, os valores para a mortadela produzida com carne de frango são maiores do que as de carne suína. Isso ocorre devido à quantidade adicionada de proteína de soja, proteína de carne muscular e de amido ser maior na mortadela produzida com carne de frango.

\section{Conclusão}

Baseado nos resultados de $\mathrm{A}_{\mathrm{w}}, \mathrm{pH}$ e textura das mortadelas produzidas com carne suína e com carne de frango, conclui-se que não houve diferenças significativas em relação à qualidade das mortadelas, independente do processo de cozimento, sendo viável elaborar as mortadelas com redução no tempo de processo e aumento da temperatura. Portanto, independentemente das condições da temperatura inicial da massa das mortadelas, o processo de cozimento pode ser aplicado em nível industrial.

\section{Agradecimentos}

Os autores agradecem ao Programa de Pós-Graduação em Engenharia de Alimentos da URI - Campus de Erechim.

\section{Referências}

1. Troy DJ, Kerry JP. Consumer perception and the role of science in the meat industry, Meat Sci. 2010; 86(1): 214-226. 
2. Tavares TM, Serafini AB. Carnes de hambúrgueres prontas para consumo: Aspectos legais e riscos bacterianos. Rev. Patol. Trop. 2006; 35(1): 17-23.

3. Rinaldi M, Chiavaro E, Gozzi E, Massini R. Simulation and experimental validation of simultaneous heat and mass transfer for cooking process of Mortadella Bologna PGI. Int. J. Food Sci Technol. 2011; 46: 586-593.

4. Toldrá F. Handbook of Fermented Meat and Poultry. $2^{\circ}$ Ed., John Wiley \& Sons, 2014, 528 p.

5. Martins LL, dos Santos IF, Franco RM, De Oliveira LAT, Bezz J. Determination of pH and activity water (aw) and relation between the with the bacteriological profile the samples bovine and chicken "hot dog" sausages that are vacuumed and retail commercialized and comes from supermarkets in Rio de Janeiro and Niterói - RJ. Rev. Bras. Ciênc. Vet. 2011; 18 (2/3): 92-96.

6. Benelli J, Toniazzo G, Prestes RC. Tres MV. Development and utilization of pork skin emulsion in mortadella as a soy protein substitute. Int. Food Res. J. 2015; 22(5): 2126-2132.

7. Piqueras-Fiszman B, Spence C. The influence of the feel of product packaging on the perception of the oralsomatosensory texture of food. Food Qual. Prefer. 2012; 26 (1): 67-73.

8. Chesnokova AV, Radina OI, Serdyuk RI. Consumer loyalty as a factor of establishing the competitive advantages in a company under the market conditions. Asian Social Sci. 2014; 10( 23): 255-260.

9. Official methods of analysis (16th ed.), Association of Official Analytical Chemists, Washington, DC (1995).

10. Brasil Ministério da Agricultura, Pecuária e Abastecimento. Secretaria Nacional de Defesa Agropecuária. Laboratório Nacional de Referência Animal (LANARA). Métodos analíticos oficiais para controle de produtos de origem animal e seus ingredientes. II. Métodos Físico-Químicos. Brasília. 1981.

11. Viuda-Martos M, Ruiz-Navajas Y, Fernández-López J, Pérez-Álvarez JA. Effect of added citrus fibre and spice essential oils on quality characteristics and shelf-life of mortadella, Meat Sci. 2010; 85(3): 568-576.

12. Fiorda FA, De Siqueira MID. Avaliação do pH e atividade de água em produtos cárneos, Estudos. 2009, 36 (5): 817-826.

13. Barretto ACS; Pollonio MAR. Aplicação de fibras como substituto de gordura em mortadela e influência sobre as propriedades sensoriais. Hig. aliment. 2009; 23(174/175): 181-188.

14. Wilson EA, Demmig-Adams B. Antioksidant, anti-inflammatory and antimicrobial properties of garlic and onions. Nutritive and Food Science, 2007; 37(3):178-183.

15. Dewi M, Huda N, Ismail N. Use of fresh garlic and garlic powder in duck sausage during refrigerated storage. J. Food and Ag-Ind. 2010; 3(5): 526-524.

16. Cheng JH, Wang ST, Ockerman HW. Lipid oxidation and color change of salted pork patties. Meat Sci. 2007; 75 (1): 71-77.

17. Saldaña E, Behrens JH, Serrano JS, Ribeiro F, De Almeida MA, Contreras-Castillo CJ. Microstructure, texture profile and descriptive analysis of texture for traditional and light mortadella, Food Struct. 2015, in press. 